\title{
Reflexiones en torno al proyecto de ley (Boletín No 9895-11) que Regula la Despenalización de la Interrupción Voluntaria del Embarazo en Tres Causales
}

\author{
Gladys Bórquez Estefó ${ }^{1}$, Lionel Bernier Villarroel ${ }^{2}$, Mauricio Besio Rollero ${ }^{3}$, Julio Montt \\ Momberg 4 , Fernando Novoa Sotta 5 , Sofía Salas Ibarra 6 , Rodrigo Salinas Ríos 7 , Carlos \\ Valenzuela Yuraidini ${ }^{8}$, Adelio Misseroni Raddatz ${ }^{9}$. Departamento de Ética, Colegio Mé- \\ dico de Chile (A.G.).
}

\footnotetext{
1 Directora Médica, Clínica Hospital del Profesor. ${ }^{2}$ Departamento de Bioética y Humanidades Médicas, Facultad de Medicina, Universidad de Chile. ${ }^{3}$ División de Obstetricia y Ginecología, Escuela de Medicina, Facultad de Medicina, Pontificia Universidad Católica de Chile. ${ }^{4}$ Primer Director del Programa Regional de Bioética OPS, Ex Ministro de Salud, Ex Presidente Departamento de Ética, Colegio Médico de Chile A.G. ${ }^{5}$ Departamento de Neuropediatría, Universidad de Valparaíso. ${ }^{6}$ Facultad de Medicina y Programa de Ética y Políticas Públicas en Reproducción Humana, Universidad Diego Portales. ${ }^{7}$ Departamento de Ciencias Neurológicas, Universidad de Chile. ${ }^{8}$ Programa de Genética Humana, ICBM, Facultad de Medicina, Universidad de Chile. ${ }^{9}$ Departamento Jurídico, Colegio Médico de Chile (A.G.).
}

\section{INTRODUCCIÓN}

El proyecto de ley que "regula la despenalización de la interrupción voluntaria del embarazo en tres causales" y que se originó en Mensaje enviado por la Presidenta de la República doña Michelle Bachelet Jeria a la Cámara de Diputados, con fecha 31 de enero de 2015 (1), ha suscitado en nuestro país un amplio debate sobre el aborto, en el cual han participado distintos actores sociales, incluyendo al gremio médico y al Departamento de Ética del Colegio Médico de Chile.

En el presente documento discutiremos brevemente las tres causales de interrupción del embarazo que contempla el referido proyecto de ley, planteando los requerimientos técnicos y algunas dificultades que se aprecian para su implementación en nuestro país.

Cabe hacer presente que en nuestro Departamento de Ética se encuentran representadas distintas visiones sobre la licitud moral del aborto y el grado de protección que debe darse a la vida humana embrionaria y fetal. Los integrantes de este Departamento representamos diversas creencias e ideas y apreciamos la diversidad como un bien, lo que nos ha permitido escucharnos unos a otros.
No obstante, reconocemos la dificultad que existe en lograr consenso en ciertos aspectos filosóficos relacionados con el estatuto ontológico del embrión humano, por lo que, de manera deliberada, hemos soslayado en este documento la discusión sobre esta materia.

\section{CONCEPTOS GENERALES}

La Organización Mundial de la Salud ha definido aborto como la interrupción del embarazo cuando el embrión o feto todavía no es viable fuera del útero (2), es decir, antes de completadas las 20 semanas de edad gestacional o, si ésta es desconocida, cuando el embrión/feto pesa menos de $400 \mathrm{~g}$ (3).

La discusión sobre el aborto suele darse entre posturas antagónicas que representan visiones irreconciliables del problema.

Por un lado, están aquéllos que consideran que se debe proteger la vida humana desde la fecundación y hasta la muerte natural; en consecuencia, ninguna situación, por grave que sea, podría justificar dar muerte a un ser humano inocente.

Otra postura señala que la mujer tiene plena autonomía sobre su cuerpo y que sólo ella puede 
tomar decisiones respecto de lo que le atañe; por lo tanto, el aborto libre es su derecho. Esta postura se apoya en diversas normas internacionales de derechos humanos, que reconocen que el acceso a abortos legales y seguros es fundamental para el disfrute y el ejercicio efectivos de los derechos humanos por parte de mujeres y jóvenes.

A su vez, el Comité de las Naciones Unidas para la Eliminación de la Discriminación contra la Mujer ha expresado preocupación respecto de la relación existente entre las leyes restrictivas en materia de aborto, los abortos clandestinos y los riesgos para la vida, la salud y el bienestar de mujeres y jóvenes (4).

Una tercera postura considera que el estatuto ontológico del embrión otorga a éste derechos de manera progresiva, diferenciando el grado de protección que aquél merece en relación con un feto maduro o un recién nacido. Tal punto de vista puede tener repercusiones en la aproximación que sus partidarios tengan frente a los tres casos de aborto permitido que el proyecto de ley contempla. De hecho, esta distinción subyace en nuestra legislación, que señala penas de menor entidad para el delito de aborto en relación con las contempladas para el infanticidio y demás formas de homicidio.

Adicionalmente, existe preocupación porque se vulnera el principio de justicia cuando mujeres de mayores recursos pueden viajar al exterior en busca de un aborto legal y seguro, mientras que aquéllas de menores ingresos no pueden hacerlo.

En contraposición a estas visiones antagónicas, existe una mirada intermedia, la cual reconoce que, en determinadas circunstancias -como algunas de las que menciona este proyecto de ley-, existe un genuino conflicto de intereses o valores entre el respeto a la autonomía de la mujer y los intereses de la criatura que está por nacer.

Este proyecto de ley busca, por lo tanto, "resolver un conflicto entre bienes que son inconmensurables", reconociendo que las tres causales de despenalización que contempla constituyen situaciones extremas. Tal como señala la Asociación Médica Mundial en la Declaración de Oslo sobre aborto terapéutico (5), "las circunstancias que ponen los intereses de la madre en conflicto con los intereses de su criatura por nacer crean un dilema y plantean el interrogante respecto a si el embarazo debe o no ser deliberadamente interrumpido", reconociendo que la diversidad de respuestas a esta situación es, a fin de cuentas, una cuestión de convicción personal e individual, que debe ser respetada. Asimismo, esta Declaración señala que “.....no es función de la profesión médica determinar las actitudes y reglas de una nación o de una comunidad en particular con respecto a este asunto, pero sí es su deber asegurar la protección de sus pacientes y defender los derechos del médico en la sociedad".
Por lo tanto, tal como hemos señalamos en el documento titulado "Posición del Departamento de Ética del Colegio Médico de Chile a propósito de la discusión legislativa sobre aborto", de junio de 2014, "la determinación de aquellas circunstancias en que sea lícita la interrupción del embarazo corresponde al Parlamento, ya que es éste el órgano que representa a los ciudadanos en una sociedad democrática".

A continuación, analizaremos los tres casos de aborto lícito contemplados en el proyecto de ley en estudio.

\section{Primera Causal: Riesgo vital, presente o futuro, de la mujer, de modo que la interrupción del em- barazo evite un peligro para su vida}

La finalidad de esta indicación es "permitir que la mujer tenga acceso a los tratamientos médicos necesarios para preservar su vida, aun cuando la realización de los mismos implique la interrupción del embarazo". En este caso no existe la intención de provocar la muerte embrionaria o fetal y, para algunos médicos, si no existe tal intención primaria de matar al feto, no habría, en consecuencia, aborto; no obstante, la mayoría de los integrantes de este Departamento suscribe la definición que la Organización Mundial de la Salud ha dado sobre aborto, la cual no califica intenciones.

Este riesgo de vida puede presentarse antes de las 20 semanas de gestación y, para resolverlo, se requiere realizar un aborto con un feto probablemente inviable ex útero, o luego de las 20 semanas, con el consiguiente nacimiento de un prematuro extremo, que puede o no ser viable con los cuidados médicos disponibles. En este primer caso el objetivo no sería provocar la muerte del embrión/ feto, sino que realizar una acción médica que procura salvar la vida materna.

Desde un punto de vista ético, esta causal de aborto ha sido justificada en base a dos principios o doctrinas:

a) La doctrina del doble efecto, que se da al existir una patología que no es de origen fetal -como infección ovular, tumor placentario, entre otras- que hace imposible la continuidad del embarazo sin la muerte o daño severo de la madre. En tal situación la muerte del feto es un efecto secundario, no deseado, del tratamiento requerido para tratar la condición.

b) La doctrina del mal menor o del único bien posible, cuando es el feto el que directa o indirectamente genera el daño materno. En este caso, el obstetra se ve enfrentado a la decisión de poner término al embarazo para salvar a la madre o permitir su curso natural, con la consiguiente muerte de ambos. Aquí no hay alternativa posible, de todas formas el feto morirá, ya sea secundariamente como consecuencia del procedimiento médico, o in 
útero, al morir la madre, de ahí su denominación de "doctrina del único bien posible".

Por lo tanto, en el caso de riesgo vital de la madre, la lex artis indica que hay que interrumpir el embarazo, exista o no legislación que lo permita expresamente; concordante con esto, la doctrina penal nacional estima que existirían normas de carácter general que justifican o exculpan al médico en caso de aborto terapéutico.

Sin embargo, tal como ha expresado el Colegio Médico de Chile en documento de junio de 2014 de este Departamento de Ética, al que hemos hechos referencia previamente, las opiniones de los autores sobre esta temática son variadas, lo cual hace evidente la necesidad de su revisión por parte del órgano legiferante, pues no son admisibles tales ambigüedades interpretativas en materia punitiva, siendo una exigencia constitucional la determinación precisa de aquellas conductas que están vedadas o permitidas a los profesionales de la salud. La ley debe ser clara en consagrar la licitud de la interrupción del embarazo cuando su prosecución pueda significar un peligro serio para la vida o salud de la gestante. Por consiguiente, el Departamento de Ética del Colegio Médico de Chile estima necesario introducir en nuestro ordenamiento jurídico una norma que, expresamente, excluya la punibilidad del aborto por razones terapéuticas.

El proyecto de ley en estudio, al tratar esta primera causal, autoriza la interrupción del embarazo cuando exista peligro para la vida de la mujer, no sólo en caso de riesgo vital presente, sino que también futuro. Se trata, esta última, de una situación que puede ser difícil de determinar y cuyo alcance no se explicita en el proyecto. Podríamos entender que se refiere a aquella condición de salud de la madre que presumiblemente se agravará si continúa con el embarazo, pudiendo significar un riesgo vital en un futuro impreciso, incluso después de ocurrido el parto. Esta situación requiere de una mayor precisión diagnóstica y, dado lo impredecible del curso de ciertas enfermedades crónicas, no siempre es posible determinar con certeza que la condición se agravará producto del embarazo. En este sentido, nos parece más conveniente eliminar esta mención del proyecto de ley y que sea el equipo médico, en conjunto con la embarazada, quienes determinen el mejor curso de acción ante situaciones específicas.

Para que la embarazada pueda tomar decisiones autónomas es prerrequisito la entrega adecuada de información a la mujer, en los términos que establece la Ley $\mathrm{N}^{\circ} 20.584$ sobre derechos y deberes de los pacientes para el consentimiento informado. En este sentido, se requiere de un diagnóstico lo más certero y oportuno posible, para que el médico tratante pueda otorgar dicha información.

En relación con el acceso adecuado a la prestación de salud, es necesario el concurso de espe- cialistas médicos y la implementación de la infraestructura y equipamientos adecuados, debiendo ser realizado el procedimiento por un médico competente en la materia y en un lugar aprobado por las autoridades del caso, tal como señala la Declaración de la Asociación Médica Mundial a que nos hemos referido previamente. En este sentido, creemos que el manejo de una embarazada que está en riesgo vital debe ser hecho por un médico especialista, exigencia que no contempla el proyecto de ley, pero que debería incorporar en forma expresa. Asimismo, el procedimiento de aborto debiese ser realizado por un médico gineco-obstetra, en un lugar que cuente con el equipamiento necesario para enfrentar eventuales complicaciones, idealmente en un centro de salud terciario, puesto que estamos ante situaciones que implican un grave riesgo materno, a menos que se trate de una urgencia no derivable.

\section{Segunda Causal: Embrión o feto que padezca una alteración estructural congénita o genética incompatible con la vida extrauterina}

Para contribuir a la clarificación de las indicaciones médicas que podrían dar lugar a esta segunda causal, se realizaron dos reuniones (4 de febrero y 11 de marzo de 2015) y un seminario (20 de marzo de 2015), entre el Departamento de Ética y médicos especialistas representantes de las Sociedades de Medicina Materno Fetal, de Obstetricia y Ginecología, de Genética y de Pediatría, con sus Ramas de Neonatología y Genética Clínica.

A continuación, señalaremos una denominación y una definición que nos parecen más acertadas para dar cuenta de la causal en análisis:

Anomalía fetal incompatible con la vida extrauterina: es todo defecto estructural o funcional que compromete seriamente uno o más órganos vitales imprescindibles para la vida extrauterina, que no son reemplazables o recuperables con las herramientas médicas o quirúrgicas actualmente disponibles, y que determina invariablemente la muerte durante el periodo fetal o tras el nacimiento, o que previsiblemente se asocia con un tiempo de supervivencia breve, aunque en condiciones muy excepcionales la supervivencia pudiese ser mayor, pero inevitablemente con una muy mala calidad de vida.

En relación con la oportunidad y precisión del diagnóstico prenatal, estimamos pertinente efectuar las siguientes consideraciones:

Diagnóstico ecográfico: según las normas de control prenatal del Ministerio de Salud, se efectúan 4 ecografías a la mujer embarazada: entre las 7-11 semanas, entre las 11-13, entre las 18-24 y entre las 32-35. La posibilidad real de hacer un diagnóstico de anomalías severas antes de las 11 semanas es prácticamente excepcional. Entre las 
11 y 13 semanas, con un feto que mide 5 a $8 \mathrm{~cm}$ de longitud, ya es posible efectuar un diagnóstico más certero, particularmente de algunas anomalías estructurales como acráneo, holoprosencefalia alobar y algunas uropatías obstructivas, entre otras. Dado que las imágenes dependen de la interpretación que efectúa el examinador, esto es posible en manos de expertos especialistas en medicina materna fetal y con equipos ecograficos 3D de alta resolución, los que no están disponibles en todo el país. En el segundo trimestre, con un feto de 500 g y $30 \mathrm{~cm}$ de longitud, es posible hacer otros diagnósticos de forma más precisa. Respecto de estas anomalías, nos parece adecuado que sean las sociedades científicas las que definan, a nivel de sus comités, el listado de anomalías que cumplan con la definición planteada, el cual debiera ser modificado según los avances de la medicina clínica.

Diagnóstico genético: La etiología de las anomalías fetales es genética-ambiental; las hay preferentemente ambientales por teratógenos y preferentemente genéticas por uno o dos genes (más de 5000 actualmente), por varios genes (multifactoriales), por alteraciones cromosómicas o epigenéticas. Los embarazos con fetos de alto riesgo de patología genética se plantean cuando hay antecedentes familiares, pero una proporción importante proviene de casos no familiares y se sospecha patología genética por alteraciones del desarrollo fetal, del embarazo o anomalías descubiertas en las ecografías. En caso de sospecha de una patología genética durante el embarazo, puede realizarse un diagnóstico por estudio de vellosidades coriales (8 a 11 semanas con riesgo de aborto de 1 a $3 \%$ ); por amniocentesis (15 a 18 semanas, con riesgo de aborto de 0,5 a $1 \%$ ); por cordocentesis (punción venosa del cordón umbilical desde las 20 semanas, riesgo aborto $3 \%$ ) y por células o ADN fetales circulantes en la sangre de la madre (sin riesgo de aborto, no disponible aún en Chile). El acierto diagnóstico varía mucho con el tipo de muestra o de examen, desde simple visión al microscopio hasta técnicas moleculares complejas y de alto costo. Si bien una parte importante de las anomalías fetales se debe a alteraciones cromosómicas, hay anomalías fetales que no proceden de ellas y hay anomalías cromosómicas que no producen malformaciones. La mayor parte de las malformaciones congénitas (cerca del $6 \%$ al nacimiento; labio leporino, displasia de cadera, pie contrahecho, anencefalia, cardiopatías operables, malformaciones del pabellón auricular, malformaciones de órganos, etc.) se deben a múltiples genes (multifactoriales) y no corresponden a síndromes relacionados con anomalías cromosómicas: su viabilidad con tratamientos adecuados se aproxima a la normal. Entre las enfermedades genéticas multifactoriales se encuentran aquéllas que afectan a la mayor parte de la población de niños, adolescentes y adultos (diabetes, obesidad, hipertensión, cáncer, etc.).

Desde la epidemiología y demografía de estas malformaciones y genopatías, debemos considerar que al nacimiento hay cerca de un $0,5 \%$ de anomalías cromosómicas, de las cuales algunas, como traslocaciones balanceadas, síndrome XXY (Klinefelter) y síndrome $X Y Y$, tienen expectativas de vida casi iguales a las normales; la trisomía 21 (Down) y el síndrome X0 (Turner) tienen expectativas de vida algo inferiores; las trisomías 13 y 18 generan síndromes asociados a malformaciones y presentan viabilidad menor a 5 meses. Las "patologías" genéticas monogénicas se dan en cerca del $10 \%$ de los recién nacidos y presentan una variedad amplia de compromiso vital. Así, la ceguera a los colores (Daltonismo) presenta viabilidad similar a la normal; el albinismo y la hemocromatosis (hay varios tipos) presentan viabilidades algo inferiores; la hemofilia, la fibrosis quística, presentan menor viabilidad que la normal dependiendo de la mutación específica; en la fibrosis quística hay mutaciones con viabilidades de varias décadas y algunas muy graves con viabilidades inferiores a 15 años. Varias hemoglobinopatías y deficiencias inmunitarias severas presentan viabilidades inferiores al año.

Así las cosas, esta segunda causal contemplada en el proyecto de ley en estudio se refiere a patologías genéticas monogénicas graves (como hemoglobinopatías), a patologías multifactoriales con malformaciones fetales graves (incluidas las monstruosidades, sin alteraciones cromosómicas) y a alteraciones cromosómicas sindrómicas con malformaciones severas (y algunas monstruosidades como los triploides), y que pueden estar en el orden de 2 por mil nacidos, es decir unos 500 casos anuales en Chile.

Cabe considerar que la patología genética se da con heterogeneidad (muchos modelos genéticos dan la misma anomalía), expresividad variable (la misma enfermedad genética presenta diversos grados de compromiso vital) y penetrancia incompleta (un individuo que tiene el genotipo para esa enfermedad puede no presentarla). La penetrancia incompleta produce el caso dramático que una madre que no presenta la enfermedad dominante pero tiene el genotipo tendrá la mitad de sus hijos con la enfermedad.

Podemos apreciar que hay, a lo menos, dos fuentes de incertidumbre para estimar el riesgo vital del feto o del recién nacido:

a) Limitaciones de las técnicas diagnósticas, por cuanto: i) son especificas para ciertas patologías y no otras; ii) son de alto costo; iii) en su mayoría son invasivas; iv) sus resultados son de difícil interpretación, como sucede, por ejemplo, en caso de mosaicismo, y v) detectan susceptibilidades, lo que es algo difícil de comprender para los pacientes. 
b) Variabilidad que la patología -detectada o no- presenta con respecto al riesgo vital, debido al genoma residual de ese individuo (aquél no relacionado con la patología que modifica la expresión de esos genes), y al ambiente en que se desarrolla ese feto o recién nacido.

El presente proyecto no establece plazos para interrumpir el embarazo por esta causa. En todo caso, si luego de realizado el procedimiento abortivo el feto naciere vivo, se le deberán otorgar aquellos cuidados que fueren apropiados a su condición, respetando el principio de proporcionalidad terapéutica.

Es necesario señalar que no todos los médicos concuerdan con la introducción de esta segunda causal de aborto. Para algunos, inducir un parto prematuro no hace más que adelantar una muerte embrionaria o fetal inevitable, y consideran inadecuado obligar a una madre con feto inviable a completar el embarazo para que el niño muera pocas horas después del parto. Otros médicos, en cambio, consideran que un aborto por esta causal pone fin anticipado a una vida humana.

Reconociendo este desacuerdo moral -que también está presente al interior de nuestro Departamento-, queremos discutir algunas dificultades técnicas respecto de esta indicación.

Si deseamos asegurar condiciones adecuadas para la toma de decisión de una mujer embarazada que tiene un embrión o feto con alteraciones estructurales severas e incompatibles con la vida extrauterina, debemos ser capaces de contar con un equipo médico especialista y multiprofesional que realice un diagnóstico prenatal precoz y oportuno, incluyendo acceso a técnicas de diagnóstico genético. Asimismo, con posterioridad a la información y decisión de la mujer embarazada, se debe asegurar a ésta un adecuado acompañamiento y apoyo psicológico, tanto para aquéllas que deciden abortar como para quienes deciden llevar a término el embarazo.

Es necesario señalar que esta causal podría entrar en conflicto con el artículo $8^{\circ}$ del Código de Ética del Colegio Médico (6), contemplado en el Título II, de este cuerpo normativo, que se refiere a los "Deberes generales del médico", y que señala lo siguiente:

"El respeto de la vida humana desde su inicio y hasta su término constituye el fundamento básico del ejercicio profesional médico. Toda intervención médica realizada durante los nueve meses de gestación deberá velar siempre por el mejor interés de la madre y del hijo".

Por lo tanto, esta segunda causal del proyecto de ley coloca al equipo médico en un genuino dilema moral, puesto que es difícil conciliar los intereses de la madre que no desea seguir adelante con un embarazo cuyo resultado final será la muerte fetal, o del recién nacido, con el acto médico que debe procurar un bien para ambos pacientes (madre e hijo), como señala nuestro Código de Ética. Algunos médicos argumentan que si de todas maneras ese embrión/feto ha de morir prontamente, hacerlo antes no parece perjudicarlo en modo alguno, pero otros consideran difícil de aceptar que provocar la muerte de ese paciente sea un acto beneficiente. De hecho, la eutanasia no voluntaria es resistida incluso por aquellos que están de acuerdo con la muerte a petición del enfermo.

\section{Tercera Causal: Embarazo producto de una vio- lación}

El proyecto de ley establece, a este respecto, lo siguiente: "Mediando la voluntad de la mujer, un(a) médico(a) cirujano(a) se encuentra autorizado(a) para interrumpir un embarazo cuando: (...) 3) Es resultado de una violación, en los términos del inciso segundo del artículo siguiente, siempre que no hayan transcurrido más de doce semanas de gestación. Tratándose de una menor de 14 años, la interrupción del embarazo podrá realizarse siempre que no hayan transcurrido más de dieciocho semanas de gestación".

En estos casos, según señala el Mensaje con que fue enviado el proyecto de ley en cuestión, el embarazo ha sido consecuencia de una relación sexual realizada contra o sin la voluntad de la mujer, mediante violencia o coerción. Agrega que no se puede exponer a la mujer a "someterse a un proceso penal, como condición para interrumpir su embarazo. Cuando una mujer ha sido víctima de violencia sexual, debe primar su protección y bienestar, sin que se pierda de vista que la prestación médica no puede depender de los resultados de un proceso penal".

El proyecto de ley preceptúa que, en el caso de la indicación en análisis, "un equipo de salud, especialmente conformado para estos efectos, evaluará e informará la concurrencia de los hechos que la constituyen. En el cumplimiento de su cometido dicho equipo deberá dar y garantizar a la mujer un trato digno y respetuoso".

Resulta pertinente señalar que los artículos 362 y 363 del Código Penal consideran que existe violación en los siguientes casos: i) cuando se usa fuerza o intimidación; ii) cuando la víctima se halla privada de sentido, o cuando se aprovecha su incapacidad para oponer resistencia; iii) cuando se abusa de la enajenación o trastorno mental de la víctima, y iv) cuando se trata de una menor de catorce años, aun cuando no concurra ninguna de las circunstancias antes señaladas.

A nuestro juicio, resulta altamente gravoso imponer al equipo de salud la carga de evaluar e informar la concurrencia de los hechos que constituyen 
la causal, y consideramos que será de gran dificultad acreditar adecuadamente su concurrencia, especialmente en los casos señalados en los puntos i) y ii) precedentes.

En efecto, cuando el embarazo ha sido producto de una relación sexual realizada abusando de la enajenación o trastorno mental de la mujer, o con una menor de catorce años, no existirán probablemente mayores dificultades para tener por configurada esta tercera causa de aborto permitido.

Sin embargo, en los casos de violación por fuerza o intimidación, o cuando la víctima se hallare privada de sentido, o se aprovechare el victimario de su incapacidad para oponer resistencia, pudiera ser difícil de determinar su concurrencia, especialmente si sólo se cuenta con la declaración de la mujer embarazada. ¿En base a qué elementos técnicos podría el médico determinar que la solicitud de interrupción del embarazo que la mujer efectúa se encuadra en esta causal de aborto? ¿Debe el médico denunciar el delito o debe primar el deber de confidencialidad que existe en toda relación médico-paciente?

El proyecto de ley efectúa una mención especial respecto de las menores de 14 años, en cuyo caso la interrupción del embarazo requiere, además de su voluntad, la autorización del representante legal, pudiendo eximirse de ella si el equipo de salud considera que existen antecedentes que hagan sospechar que al hacerlo, se expone a la menor a mayores riesgos de violencia en el hogar.

En efecto, el proyecto señala que si a juicio "del médico(a) cirujano(a) existan antecedentes para afirmar que la solicitud de autorización al representante legal generará para la menor de 14 años un riesgo de violencia intrafamiliar, coacción, amenaza o maltrato, o una posible situación de desarraigo o de abandono, se prescindirá de ésta y se solicitará una autorización sustitutiva al Tribunal de Familia competente, el que deberá pronunciarse conforme al procedimiento establecido en el inciso anterior".

Por otra parte, el proyecto establece un plazo máximo de 12 semanas para permitir la interrupción del embarazo, por esta causa, en mujeres de 14 o más años, mientras que para las menores de 14 establece un término mayor, de 18 semanas. No se aprecia que existan motivos fundados para realizar tal distinción, más allá de una razón práctica, cual es que, en el caso de las menores de 14 años, el diagnóstico de embarazo suele ser tardío, ya sea porque la niña no se percata de su gravidez o porque la oculta. Con todo, no parece existir una justificación de fondo para aumentar hasta 18 semanas el límite gestacional en estos casos, pudiendo ser considerado como excesivo, además de someter a la menor a un riesgo mayor durante la realización del procedimiento abortivo.

Por otra parte, respecto de las menores de 14 años, el proyecto de ley preceptúa que "a falta de la autorización del representante legal, la menor, asistida de un integrante del equipo de salud, podrá solicitar la intervención del Tribunal de Familia competente para que constate la concurrencia de la causal", agregando que "el Tribunal autorizará la interrupción del embarazo, sin forma de juicio y verbalmente, a más tardar dentro de las 48 horas siguientes a la presentación de la solicitud, con los antecedentes que le proporcione el equipo de salud, oyendo a la menor y, si lo estimare, al integrante de éste que la asista".

Como bien sabemos, tratándose de una menor de 14 años la relación sexual que ha dado origen al embarazo constituirá siempre violación, por lo que el Tribunal debiera abocarse más bien a proteger adecuadamente los intereses de la niña y, considerando el carácter irreversible de la medida, sería deseable que sea asistida por un equipo de salud multidisciplinario, que incluya consejería y apoyo sicológico, evaluación de la situación familiar, entre otros factores, antes de proceder a la interrupción del embarazo.

En el caso de la adolescente menor de edad, pero que ya ha cumplido 14 años, el proyecto señala que “(...) podrá manifestar por sí su voluntad para la interrupción de su embarazo. Su representante legal o uno de ellos a su elección, si tuviere más de uno, deberá ser informado de su decisión".

Estimamos del todo pertinente reflexionar sobre la evaluación que, de la autonomía de la menor, debe efectuarse para tomar decisiones de esta naturaleza, siguiendo la doctrina del "menor maduro". El solo hecho de tener 14 años ya cumplidos no permite concluir, necesariamente, que tiene la capacidad para adoptar esta decisión de manera autónoma.

Como veremos más adelante, el proyecto de ley privilegia el deber de confidencialidad de la atención médica por sobre el deber de denuncia, en el caso de la mujer que causare su aborto o consintiere que otra persona se lo cause, fuera de los casos de aborto permitido que el proyecto pretende introducir. En este tercer motivo de interrupción lícita del embarazo, no queda claro si se debe privilegiar también la confidencialidad médica por sobre el deber de denuncia. Nos preocupa que la ausencia de denuncia pudiere facilitar la impunidad de muchos casos de violación, especialmente intrafamiliares.

Por otra parte, llama la atención que no se haga mención alguna en el proyecto respecto de la situación de la mujer mayor de edad que no tiene la capacidad psíquica o mental para consentir un acto sexual. El numeral $3^{\circ}$ del artículo 361 del Código Penal previene que comete violación el que accede carnalmente a una mujer cuando se abusa de su enajenación o trastorno mental, por lo que, en estos casos, el embarazo será siempre producto de una violación. Consideramos necesario, entonces, aclarar esta situación durante la tramitación del proyecto, 
para precisar si se homologará a la de una menor de 14 años, con el consiguiente aumento del plazo máximo gestacional para permitir el aborto y exigencias de autorización del representante legal, en iguales términos.

\section{Objeción de conciencia}

El Mensaje con que fue enviado al Parlamento el proyecto de ley en análisis, expresa que la objeción de conciencia "es un acto estricta y esencialmente individual del profesional clínico que deba intervenir directamente en la interrupción del embarazo, de mediar la voluntad de la mujer en los casos a que se refiere", agregando que "este derecho no puede ser un obstáculo insalvable para acceder a la interrupción del embarazo".

Esta posición es concordante con lo sostenido por la Asociación Médica Mundial en la Declaración de Oslo sobre el aborto terapéutico, en la que se sostiene que "Si las convicciones del médico no le permiten aconsejar o practicar un aborto, éste puede retirarse, siempre que garantice que un colega calificado continuará prestando la atención médica".

Coincide, asimismo, con las normas contenidas en el Código de Ética del Colegio Médico de Chile, que en su artículo 20 establece que: "El médico a quien se solicitaren prestaciones que vayan en contra de su conciencia o de su convencimiento clínico, podrá negarse a intervenir. En estas circunstancias, procurará que otro colega continúe asistiendo al paciente, salvo que ello produjere graves e inmediatos daños para la salud del enfermo".

Por la trascendencia y complejidad que reviste esta materia para la profesión médica y la sociedad en general, los fundamentos éticos y la aplicación práctica de la objeción de conciencia en el ejercicio clínico, serán profundizados por este Departamento de Ética en un documento especialmente dedicado a este aspecto del proyecto de ley.

\section{Confidencialidad de la atención médica}

El proyecto de ley en análisis privilegia el deber de confidencialidad por sobre la obligación de los profesionales de la salud de denunciar cuando notaren en una mujer señales de aborto provocado, fuera de los casos de interrupción lícita del embarazo que el referido proyecto contempla.

Concordante con esta mirada, el Departamento de Ética del Colegio Médico de Chile, en documento de junio del 2014, estimó que la legislación nacional debía excluir expresamente a los profesionales de la salud de esta obligación de denunciar a mujeres que presenten síntomas de aborto provocado, haciendo prevalecer el deber de confidencialidad que impone la deontología profesional.
Esta conclusión se fundamenta en el derecho que tiene la mujer a recibir atención de salud para tratar aquellas complicaciones derivadas de un aborto provocado, y la obligación de denunciar que contempla nuestro ordenamiento jurídico colisionaría con el deber ético de confidencialidad en la relación médico-paciente.

Por lo tanto, resulta fundamental para el acto médico que, en estos casos, el ordenamiento jurídico resguarde debidamente la confidencialidad y no imponga a los profesionales de la salud la obligación de efectuar una denuncia. Así lo reconoce, por lo demás, la inmensa mayoría de los médicos que, en la intimidad de la relación médico-paciente, recibe esta confesión. En este sentido, el deber de confidencialidad debe mantenerse aún en situaciones de aborto ilegal, aunque tal como señalan el Código de Ética y la Ley N²0.584 (7), el deber de confidencialidad no es absoluto, por lo que habrán de ponderarse adecuadamente las distintas situaciones.

Sin embargo -y como hemos señalado con anterioridad-, mantener la confidencialidad en casos de abusos de menores puede aumentar aún más su desprotección. Sobre esta materia, la Corte Suprema de nuestro país, al informar el proyecto de ley en estudio, señaló que "los deberes de confidencialidad postulados por el proyecto de ley en el Código Procesal Penal, podrían constituirse en un espacio de impunidad en desmedro de las víctimas de delitos sexuales menores de 18 años. En los fundamentos del proyecto se expresa que la mayoría de las agresiones sexuales son realizadas por parientes o cercanos a la víctima. $A$ pesar de ello, en los términos actualmente propuestos por la iniciativa, podría ocurrir que una menor de 18 años concurra una o varias veces a un establecimiento de salud y obtenga el procedimiento de interrupción del embarazo, sin que se investigue penalmente el eventual delito de violación o estupro, dado que tanto la exclusión del deber de denuncia como la primacía del deber de confidencialidad pesarán, dado los términos amplios que emplea y empleará el artículo 175 del Código Procesal Penal, tanto sobre el médico cirujano que atienda a la requirente de interrupción del embarazo, como al equipo de salud especialmente conformado al efecto que se pronuncie sobre la concurrencia de la violación. Peor aún, podría darse el caso que el propio violador, en su calidad de padre de la niña, entregue su autorización para la interrupción del embarazo, sin que se genere la investigación penal del caso"(8).

Por estos motivos, la Corte Suprema consideró conveniente revisar la exclusión de los deberes de denuncia y primacía de la confidencialidad prevista en el proyecto, a fin de resguardar el legítimo interés de la sociedad por perseguir los delitos cometidos contra menores de edad, particularmente 
en cuanto atentan contra su indemnidad sexual. En estos casos, se requiere efectuar un adecuado balance de intereses, debiendo el profesional de la salud distinguir claramente entre el deber de confidencialidad respecto de la información reservada que ha entregado la niña y la necesidad de denunciar la ocurrencia de un delito de violación.

\section{Despenalizar versus legalizar}

Existe una diferencia conceptual entre despenalización y legalización del aborto. Mientras que en el primer caso se elimina el carácter delictivo de la conducta, que continúa siendo contraria al ordenamiento jurídico, mas no penalmente sancionada, con la legalización la conducta pasa a ser lícita, debiendo en tal caso otorgar el Estado acceso oportuno y seguro a todas las mujeres que cumplan con los requisitos legales que autorizan la interrupción del embarazo.

Es del caso señalar que, si bien el proyecto de ley dice regular "la despenalización de la interrupción voluntaria del embarazo en tres causales", en realidad la consagra como una "legítima prestación de salud" y su implementación obligará a que, junto con entregar la prestación de aborto, se mejoren los estándares de atención de las mujeres, haciendo necesario incorporar en los controles de embarazo una serie de prestaciones con adecuados estándares de calidad, incluyendo, por cierto, la consejería genética, detección oportuna de malformaciones estructurales del feto mediante ecografías, derivación a centros de salud terciarios, y acompañamiento sicológico si fuese necesario.

Por lo demás, la objeción de conciencia sólo es válida en caso de legalización, careciendo de sentido si lo que se pretende es sólo despenalizar el aborto.

\section{Consideraciones finales}

El Código de Ética del Colegio Médico de Chile (9) señala, entre los deberes generales del médico, que "Toda intervención médica realizada durante los nueve meses de gestación, deberá velar siempre por el mejor interés de la madre y del hijo".

En este sentido, en la primera causal, se procura salvar la única vida que puede ser salvada, cual es la materna.

En la segunda, podemos argumentar que el mejor interés del hijo pudiera ser la interrupción del embarazo y, consecuencialmente, evitar su nacimiento o morir inmediatamente después del parto, evitando así dolor y sufrimiento o una lenta agonía, aunque otros consideren legítimamente que no es aceptable acortar deliberadamente la vida de un ser humano.
Respecto de la tercera causal, habiendo un embrión o feto sano -especialmente si la interrupción del embarazo se permite en edades gestacionales avanzadas-, resulta más difícil conciliar tal situación con lo que actualmente preceptúa nuestro Código de Ética, pues no apreciamos argumentos válidos que permitan sostener que dicha intervención vela también por el mejor interés del no nacido. En este caso, hay un evidente conflicto de intereses entre el respeto por la autonomía de la madre y la no maleficencia hacia el nasciturus.

A su vez, para la implementación práctica de esta ley, aparece como insuficiente que el proyecto señale que para "realizar la intervención en los casos regulados en las primeras dos causales, se requiere el diagnóstico de un(a) médico(a) cirujano(a) y la ratificación de dicho diagnóstico por otro profesional de iguales características". El manejo de un embarazo de alto riesgo -primera causal- y el diagnóstico de la segunda causal -malformaciones incompatibles con la vida extrauterina-, requieren de profesionales especialistas -gineco-obstetras- y manejo muchas veces en centros terciarios y con equipos multidisciplinarios, tales como genetistas, cardiólogos infantiles, neurólogos, neonatólogos, entre otros.

Asimismo, el aborto propiamente tal, especialmente en edades gestacionales avanzadas, debiese ser realizado por médicos especialistas y no por médicos generales, salvo, claro está, en situaciones de emergencia médica.

El proyecto de ley, además, impone al equipo de salud la evaluación de la concurrencia de los hechos que constituyen la tercera causal de aborto permitido, lo que muchas veces excederá el ámbito de competencia propio del médico.

Por otra parte, el manejo integral de una niña o mujer violada no sólo implica protegerla del riesgo de embarazo no deseado (por ejemplo, mediante uso oportuno de anticoncepción de emergencia), sino que también prevenir enfermedades de transmisión sexual y, muy especialmente, un acompañamiento sicológico adecuado. Creemos que este manejo integral no está adecuadamente reconocido en el proyecto de ley.

\section{CONCLUSIÓN}

Los médicos tenemos legítimo derecho a tener opiniones personales a favor o en contra de la despenalización o legalización del aborto, de acuerdo con nuestras creencias o valores. Pero estas visiones personales nunca deben ser obstáculo para que podamos contribuir al debate de políticas públicas a partir de la evidencia científica y de la concordancia con los principios éticos a los que hemos declarado adherir. 


\section{REFERENCIAS}

1. Mensaje № $1230-362$ de S.E. la Presidenta de la República, de fecha 31 enero 2015, Boletín № 9895-11. Disponible en: http://www.camara.cl/pley/pley_detaIle.aspx?prmID=10315\&prmBL=9895-11. Acceso el 20 de marzo 2015.

2. Astete C, Beca JP, Lecaros A. Propuesta de un glosario para la discusión del aborto. Rev Med Chile 2014; 142: 1449-1451.

3. Zegers-Hochschild F, Adamson GD, de Mouzon J, Ishihara O, Mansour R, Nygren K, Sullivan E, and Vanderpoel S, for ICMART and WHO. Glosario de terminología en Técnicas de Reproducción Asistida (TRA). Versión revisada y preparada por el International Committee for Monitoring Assisted Reproductive Technology (ICMART) y la Organización Mundial de la Salud (OMS). Traducido y Publicado por la Red Latinoamericana de Reproducción Asistida en 2010.

4. Centro de Derechos Reproductivos. Leyes sobre aborto en el mundo de 2014. Disponible en: http:// www.reproductiverights.org/es/document/leyes-sobre-aborto-en-el-mundo-de-2014. Acceso el 22 de marzo de 2015.
5. Declaración de Oslo de la AMM sobre el Aborto Terapéutico. Adoptada por la 24를 Asamblea Médica Mundial en Oslo, Noruega, agosto 1970 y enmendada por la $35^{\text {a }}$ Asamblea Médica Mundial en Venecia, Italia, octubre 1983 y la $57^{\text {a }}$ Asamblea General de la AMM, Pilanesberg, Sudáfrica, octubre 2006.

6. Código de Ética 2011. Colegio Médico de Chile (AG). Editado e impreso por Ediciones Tierra Mía Ltda. Santiago de Chile.

7. Ley 20.584 Derechos y Deberes que tienen las personas en relación a su atención en salud.

8. Oficio de la Corte Suprema por el cual remite opinión respecto del proyecto de ley Boletín $\mathrm{N}^{\circ}$ 9895-11. Disponible en: http://www.camara.cl/pdf. aspx?prmID=11109\%20\&prmTIPO=TEXTOSESION. Acceso el 8 de junio de 2015.

9. Código de Ética 2011. Colegio Médico de Chile (A.G.). Editado e impreso por Ediciones Tierra Mía Ltda. Santiago de Chile, p 24. 